\title{
Phase Transformations and Mechanical Properties of Fe-Mn-Si-Al TRIP-Steels
}

\author{
O. Grässel, G. Frommeyer, C. Derder and H. Hofmann \\ Max-Planck-Institut für Eisenforschung GmbH, Düsseldorf, Germany
}

\begin{abstract}
Deformation twinning, martensitic phase transformation and mechanical properties of austenitic Fe-(15$30) \mathrm{wt} \% \mathrm{Mn}$ alloys with additions of aluminium and silicon have been investigated. Tensile tests were carried out at different strain rates and temperatures. The formation of twins, $\alpha^{\prime}$ - and $\varepsilon$-martensite during plastic deformation was analysed by optical microscopy, X-ray diffraction, scanning electron microscopy (SEM) and transmission electron microscopy (TEM). The stacking fault energy $\gamma_{\mathrm{fcc}}$ and the free energy $\Delta G^{\gamma \rightarrow \varepsilon}$ for the $\gamma \rightarrow \varepsilon$ phase transformation were calculated using the regular solution model. It is known that additions of aluminium increase $\gamma_{\mathrm{fcc}}$ and therefore strongly suppress the $\gamma \rightarrow \varepsilon$ transformation while silicon decrease $\gamma_{\mathrm{fcc}}$ and sustains the $\gamma-\varepsilon$ transformation. The $\gamma \rightarrow \varepsilon$ phase transformation takes place in alloys with $\gamma_{\mathrm{fcc}} \leq 20 \mathrm{~mJ} / \mathrm{m}^{2}$. The stacking fault energy of the Fe-25Mn-3Si-3Al alloy was calculated as a function of temperature and related with microstructural changes of the strained sample at different temperatures. These steels with reduced density of about $7,3 \mathrm{~g} / \mathrm{cm}^{-3}$ combine high tensile ductility up to 80 $\%$ at high strain rates with true tensile strength of about $1000 \mathrm{MPa}$. The excellent plasticity induced by twinning and additional phase transformation up to extremely high strain rates of about $\dot{\varepsilon}=10^{3} \mathrm{~s}^{-1}$ results in an extraordinary shock resistence and enables deep drawing and backward extrusion operations of parts with complex shapes and high production rates.
\end{abstract}

\section{INTRODUCTION}

Most ferrous and nonferrous alloys for technical purposes possess stable microstructures when subjected to elastic or plastic deformation. However, there are metastable materials which are stable on cooling to low temperatures but not under mechanical load. Due to strain-induced martensitic transformation extended large necking free elongations occur in tensile tests. This transformation causes superior mechanical properties, such as high work-hardening rate, large ductility and high strength. Ultra high manganese steels exhibit the formation of mechanical twins, strain-induced $\varepsilon$ (hcp)-, and $\alpha^{\prime}$ (bcc)martensite in the $\gamma$ (fcc) matrix under internal or external stresses [1, 2]. Two different transformation paths, $\gamma \rightarrow \alpha^{\prime}$ and $\gamma \rightarrow \varepsilon \rightarrow \alpha^{\prime}$, have been reported [3]. Formation of these phases depend on the chemical composition, the test temperature and the amount of strain. The characteristics of the strain-induced microstructural changes affect the mechanical properties $[2,4,5]$.

Binary austenitic Fe-Mn alloys transform partially to $\varepsilon$ - and $\alpha^{\prime}$-martensite within a restricted composition range during cooling $[6,7]$. Additions of alloying elements to the binary Fe-Mn alloys affect their phase stability $[8,9]$. The phase transformation is correlated to the stacking fault energy $\gamma_{\mathrm{fcc}}$ in the austenitic matrix. Low stacking fault energy $\left(\gamma_{\mathrm{fcc}} \leq 20 \mathrm{~mJ} / \mathrm{m}^{2}\right)$ favours the $\gamma \rightarrow \varepsilon$ phase transformation whereas high stacking fault energy $\left(\gamma_{\mathrm{fcc}}>20 \mathrm{~mJ} / \mathrm{m}^{2}\right)$ suppresses this phase transformation [9]. Alloys with high $\gamma_{\mathrm{fcc}}$ tend to mechanical twinning formation instead of phase transformation. Additions of aluminium increase $\gamma_{\mathrm{fcc}}$ and therefore strongly suppress the $\gamma \rightarrow \varepsilon$ transformation [10]. In contrast silicon decreases $\gamma_{\mathrm{fcc}}$ and sustains the $\gamma \rightarrow \varepsilon$ transformation during cooling and deformation [11].

In this work the structural related mechanical properties of Fe-Mn alloys with addition of both aluminium and silicon were investigated. The effects of microstructural changes on work-hardening rate will be discussed. Specifically the tensile properties of the Fe-25Mn-3Si-3Al alloy were determined at different strain rates and temperatures in order to correlate microstructural features with flow stress and elongations. Deformation twinning and the formation of strain-induced martensite were analyzed. 


\section{EXPERIMENTAL PROCEDURE}

The alloys under investigation were prepared by induction-melting in an argon atmosphere and cast to round bars of $24 \mathrm{~mm}$ in diameter. The samples were swaged to $77 \%$ reduction in area and subsequently solution-treated for $2 \mathrm{hrs}$ at $1000{ }^{\circ} \mathrm{C}$ followed by water-quenching. Round tensile specimen with gage length of $25 \mathrm{~mm}$ and $5 \mathrm{~mm}$ in diameter were machined from the forged rods. Tensile tests were performed at room temperature with a strain-rate of $10^{-4} \mathrm{~s}^{-1}$. For the $\mathrm{Fe}-25 \mathrm{Mn}-3 \mathrm{Si}-3 \mathrm{Al}$ alloy additional tests were carried out at different temperatures $\left[-50{ }^{\circ} \mathrm{C} \leq \mathrm{T} \leq 400^{\circ} \mathrm{C}\right]$ and strain rates $\left[10^{-4} \leq \dot{\varepsilon} \leq 10^{3} \mathrm{~s}^{-1}\right]$. For the high strain rate tests $\left[10^{2} \leq \dot{\varepsilon} \leq 10^{3} \mathrm{~s}^{-1}\right]$ a flywheel testing facility was used [12]. Phases present were determined with X-ray diffraction. Microstructural investigations were performed by optical microscopy, scanning electron microscopy (SEM) and transmission electron microscopy (TEM). The chemical compositions of the studied alloys are presented in Table 1 together with the constituent phases before and after tensile testing.

\begin{tabular}{|c|c|c|c|c|c|c|c|}
\hline & $\begin{array}{c}\text { Mn } \\
{[\mathbf{w t} \text { ] }]}\end{array}$ & $\begin{array}{c}\text { Si } \\
{[\mathbf{w t} \%]}\end{array}$ & $\begin{array}{c}\text { Al } \\
{[\mathbf{w t} \%]}\end{array}$ & $\begin{array}{c}\mathbf{C} \\
\text { ppm }\end{array}$ & Fe & $\begin{array}{c}\text { Phases before } \\
\text { tensile tested }\end{array}$ & $\begin{array}{c}\text { Phases after } \\
\text { tensile tested }\end{array}$ \\
\hline Fe-15Mn-3Si-3Al & 17,9 & 3,2 & 2,9 & 200 & bal. & $\gamma+\alpha+\varepsilon$ & $\gamma+\alpha^{\prime}+\varepsilon$ \\
\hline Fe-20Mn-3Si-3Al & 20,1 & 2,8 & 2,9 & 400 & bal. & $\gamma+\alpha+\varepsilon$ & $\gamma+\alpha^{\prime}+\varepsilon$ \\
\hline Fe-25Mn-3Si-3Al & 26,5 & 3,0 & 2,8 & 300 & bal. & $\gamma$ & $\gamma$ \\
\hline Fe-30Mn-3Si-3A] & 29,2 & 3,0 & 2,8 & 200 & bal. & $\gamma$ & $\gamma$ \\
\hline
\end{tabular}

Table 1 : Chemical analyses of the Fe-Mn-Si-Al alloys and the constituent phases before and after tensile testing at room temperature; strain rate $\dot{\varepsilon}=10^{-4} \mathrm{~s}^{-1}$

\section{RESULTS AND DISCUSSION}

\subsection{Tensile properties and related phases of Fe-Mn-Si-Al steels}

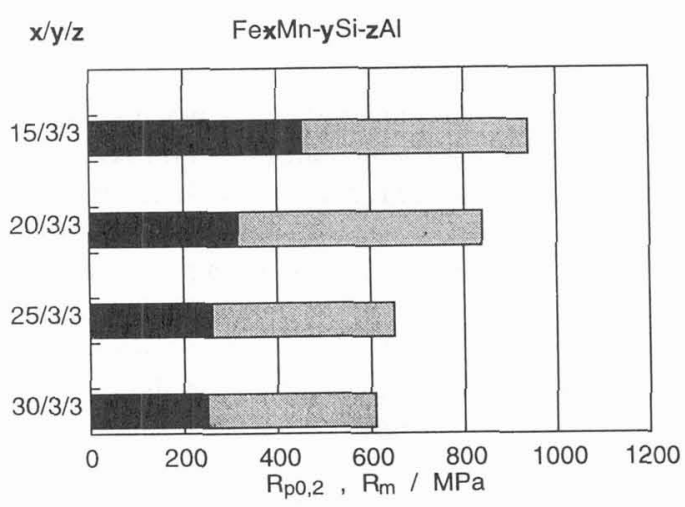

Figure 1(a): Yield stress $R_{p 0,2}$ (black marked bars) and ultimate tensile strength $R_{m}$

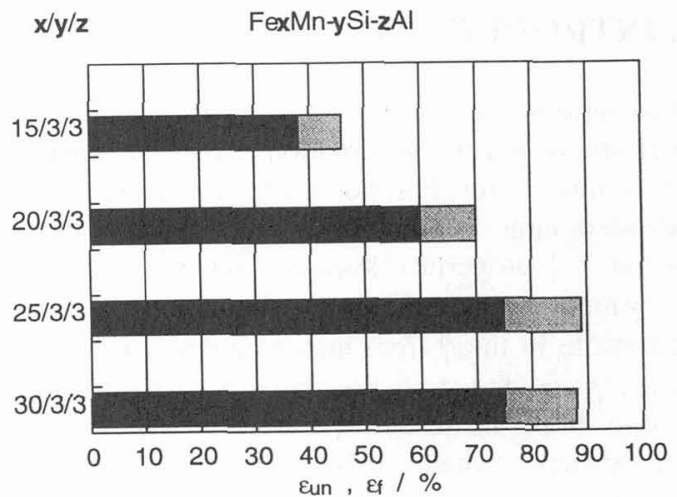

Figure 1(b) : Uniform $\varepsilon_{\text {un }}$ (black marked bars) and total elongation $\varepsilon_{\mathrm{f}}$

Mechanical properties of diverse ultra high manganese steels with $3 w t \%$ aluminium and $3 w t \%$ silicon tested in tension at room temperature; strain rate $\dot{\varepsilon}=10^{-4} \mathrm{~s}^{-1}$

Figure 1(a) illustrates that with increasing $M n$ content the ultimate tensile strength $R_{m}$ decreases from about $930 \mathrm{MPa}$ to $610 \mathrm{MPa}$. Figure 1(b) displays that the total elongation $\varepsilon_{\mathrm{f}}$ increases from $46 \%$ to $88 \%$ with increasing $\mathrm{Mn}$ content. At $\mathrm{Mn}$ contents higher than $25 \mathrm{wt} \% \mathrm{Mn}$ the total elongation is nearly constant or slighly decreasing. The coexisting phases before and after tensile testing are listed in Table 1. With 
increasing Mn content the $\alpha^{\prime}$-phase and the $\varepsilon$-phase are going to be suppressed. Volume fractions of the phases present after tensile tests could not be determind due to texture effects. The multiphase steels with the constituent $\gamma+\varepsilon+\alpha$ show phase transformations from $\gamma$ to $\varepsilon-$ and/or $\alpha^{\prime}$-martensite.

The curves of the strain hardening increment $\Delta \sigma=\sigma_{\text {true }}-\sigma_{\text {true } 5 \%}$ vs. true plastic strain $\varphi$ are presented in Figure 2. With increasing Mn content the work hardening rate increases. This is attributed to the nature of the strain-induced phase transformation. At small amouts of strain $(\varphi<0,15)$ all alloys show similar behavior. With increasing amount of strain $(\varphi>0,15)$ the alloys with 15 and $20 \mathrm{wt} \%$ Mn exhibit a change in the curvature due to the formation of strain-induced $\alpha^{\prime}$-martensite resulting in an increase in the work hardening rate. This feature of the stress-

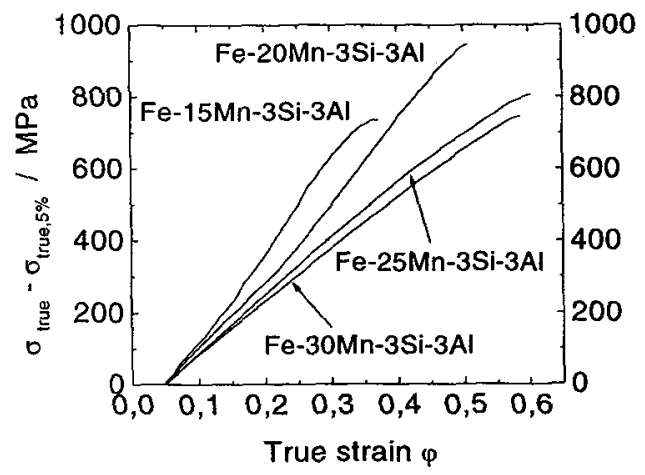

Figure 2 : Strain hardening increment vs. true plastic strain strain curve is typical for TRIP steels $[2,13,14$, 15]. Which of the transformation path: $\gamma \rightarrow \alpha^{\prime}$ or $\gamma \rightarrow \varepsilon \rightarrow \alpha^{\prime}$ is dominent have not been clarified yet. Therefore, further study has to be performed in greater detail on this subject. The alloys with 25 and 30wt\% Mn do not show similar changes in the curvature of the $\sigma_{\text {true }}-\sigma_{\text {true. } 5 \%}$ vs. true strain curves. X-ray diffraction analysis revealed that neither $\alpha^{\prime} ;$ nor $\varepsilon$-martensite was formed. However, there could be small amounts of $\varepsilon$ and/or $\alpha^{\prime}$-martensite not detectable by $\mathrm{X}$-ray diffraction due to its limited resolution. Therefore TEM studies were carried out in detail for the Fe$25 \mathrm{Mn}-3 \mathrm{Si}-3 \mathrm{Al}$ steel.

\subsection{Fe-25Mn-3Si-3Al steel}

\subsubsection{Strain rate and temperature related mechanical properties}

(a)

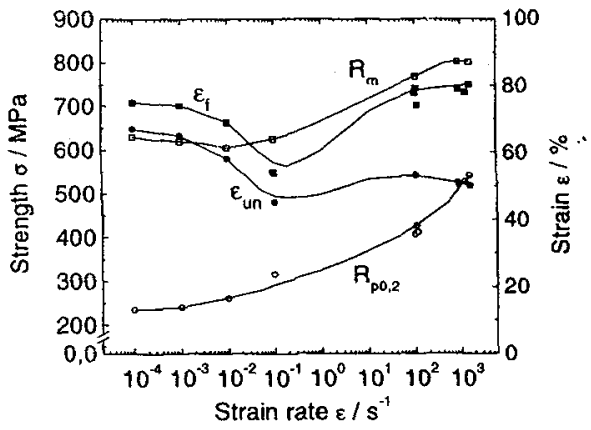

(b)

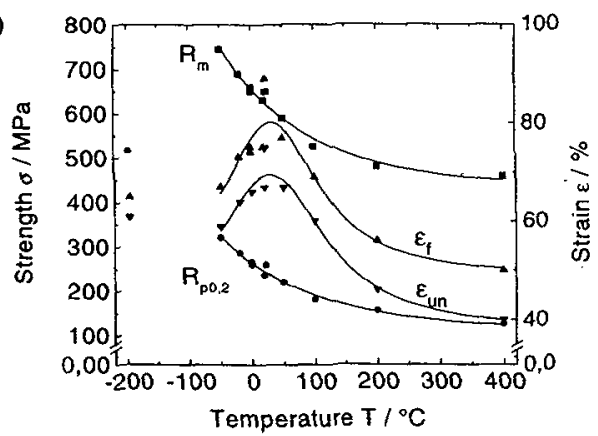

Figure 3 : Yield stress $R_{p 0,2}$, tensile strength $R_{m}$, uniform $\varepsilon_{u n}$ and total elongation $\varepsilon_{f}$ in dependence on the strain rate (a) and test temperature (b).

The change of the yield stress, tensile strength, uniform and total elongation of this steel as a function of strain rate and temperature are shown in Figure 3(a) and 3(b). With increasing strain rate the yield stress increases whereas the ultimate tensile strength is nearly constant. At strain rates beyond $10^{-2} \mathrm{~s}^{-1}$ the stress values are increasing. The uniform and total elongations decrease with increasing strain rate up to about 
$10^{-1} \mathrm{~s}^{-1}$. After reaching a relative minima the uniform elongation decreases slighly at strain rates beyond $10^{2} \mathrm{~s}^{-1}$. The total elongation reaches a maximum value of $80 \%$ at a tensile strength of $800 \mathrm{MPa}$ with a strain rate of $1,510^{3} \mathrm{~s}^{-1}$. No phase transformation were detected for this steel strained up to $10^{3} \mathrm{~s}^{-1}$.

With decreasing temperature the yield stress and the ultimate tensile strength increases. The total elongation increases from $50 \%$ at $400^{\circ} \mathrm{C}$ to a maximum value of about $80 \%$ at room temperature and decreases with lowering temperature. At $\mathrm{T}=-196{ }^{\circ} \mathrm{C}$ a tensile elongation of $65 \%$ was recorded.' X-ray diffraction measurements revealed that no detectable phase trasformation occured in tensile deformation in the temperature regime between $0^{\circ} \mathrm{C}$ and $400{ }^{\circ} \mathrm{C}$. The increasing elongation with decreasing temperature is attributed to strain-induced twinning. This causes a 'ugher strain rate sensitivity of the flow stress by multiple necking mechanism of locally strain hardeiled areas in the gage length of the tensile sample $[16,17]$. Therefore, large uniform elongation wil! be achieved because of the retardation of local necking. When a local neck will be formed, strain-irduced twinning in the $\gamma$ matrix would preferentially occured in this area. As the twin boundaries are acting as strong barriers to subsequent dislocation motion, the deformation twins lead to a strong local strain hardening. Necking will take place in other local areas which possess lower flow stress. This multiple necking mechanism results in high uniform elongations. With decreasing temperature the elongation decreases. The rate of deformation twinning increases with decreasing temperature. As a consequence, the twin formation is completed in an early stage of deformation characterized by non extended elongation. These results show that a gradual formation of deformation twins up to a large portion is necessary to enhance tensile elongation. At temperatures lower than $0{ }^{\circ} \mathrm{C}$ the formation of $\varepsilon$-martensite occured. With decreasing temperature the amount of straininduced $\varepsilon$-martensite increases. The strain-induced $\varepsilon$ martensite will be preferentially formed in a local necking region similary as the deformation twins. The high elongation of the specimen strained at $-196{ }^{\circ} \mathrm{C}$ indicates that the formation of $\varepsilon$-martensite is benefical to achieve high elongation at low temperature.

\subsubsection{Microstructures}

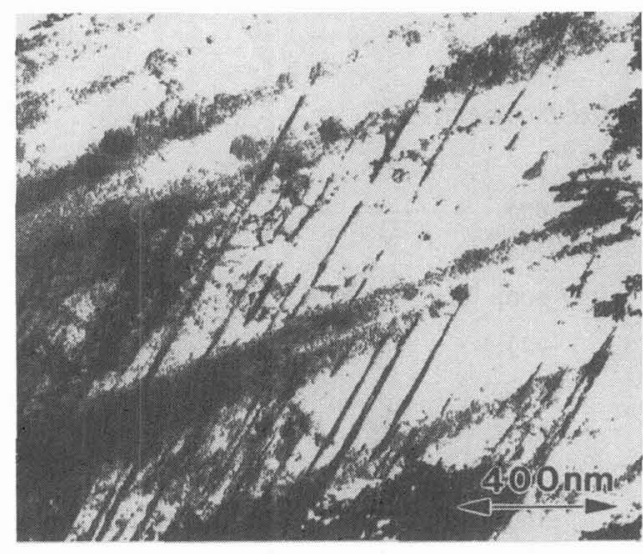

Figure 4: Bright field image showing deformation twins in the deformed material

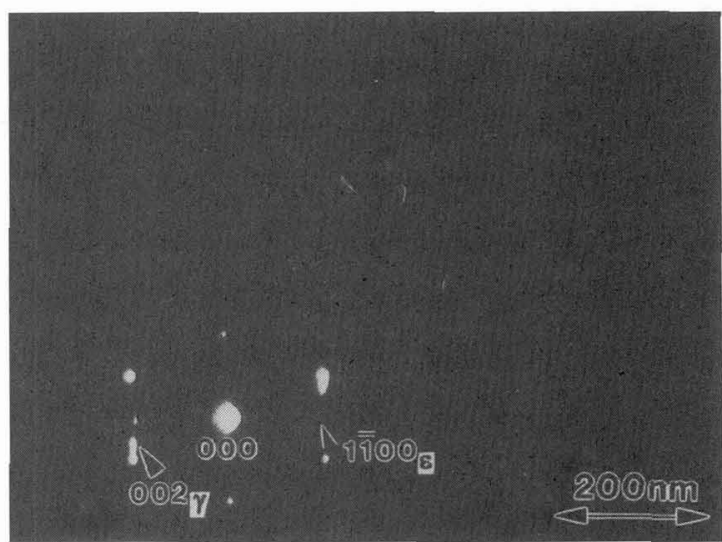

Figure 5 : Dark field image revealing a $\varepsilon$-martensite lath in the $\gamma$ matrix; $\gamma-\varepsilon$ orientation relationship is shown by the diffraction pattern

The microstructure of the undeformed sample investigated by SEM possesses an austenite with annealing twins inside the $\gamma$ grains. The fully austenitic structure is confirmed by $\mathrm{X}$-ray diffraction measurements. TEM investigations on at room temperature deformed samples show the presence of a high density of deformation twins even at the first stage of deformation. However, some $\varepsilon$-martensite has been detected in some $\gamma$ grains. Figure 4 illustrates a bright field (BF) image which shows deformation twins inside a $\gamma$ grain. The twin $(\mathrm{T})-\gamma$ matrix orientation relationship is $(111)_{\gamma} / /(111)_{\mathrm{T}}$ and $\langle 110\rangle_{\gamma} / /\langle 101\rangle_{\mathrm{T}}$. The $\varepsilon-$ 
martensite is shown in the dark field (DF) image of Figure 5. The $\gamma-\varepsilon$ orientation relationship (111) $/ /$ $(0001)_{\varepsilon}$ and $\langle 110\rangle_{\gamma} / /\langle 11 \overline{2} 0\rangle_{\varepsilon}$ is presented by the diffraction pattern. This image was taken with the $\langle 1 \overline{1} 00\rangle$ diffraction vector of the $\langle 11 \overline{2} 1\rangle_{\varepsilon}$ zone axis. It should be noted that the presence of $\varepsilon$-martensite could not be detected by $\mathrm{X}$-ray diffraction analysis.

\subsubsection{Thermodynamic calculation}

The temperature dependence of the tensile elongation of each alloy is closely related to the strain-induced phase transformation during deformation. The temperature dependence of the phase transformation is known to be related with the stacking fault energy. The tendency to form $\varepsilon$-martensite increases with decreasing stacking fault energy. Based on the regular solution model the free energy for the $\gamma \rightarrow \varepsilon$. phase transformation $\Delta G^{\gamma \rightarrow \varepsilon}$ as a function of temperature was calculated as :

$$
\begin{aligned}
\Delta G^{\gamma \rightarrow \varepsilon}= & X_{F e} \Delta G_{F e}^{\gamma \rightarrow \varepsilon}+X_{M n} \Delta G_{M n}^{\gamma \rightarrow \varepsilon}+X_{A l} \Delta G_{A l}^{\gamma \rightarrow \varepsilon}+X_{S i} \Delta G_{S i}^{\gamma \rightarrow \varepsilon}+X_{C} \Delta G_{C}^{\gamma \rightarrow \varepsilon} \\
& +X_{F e} X_{M n}\left(X_{F e}+X_{M n}\right)^{-1} \Delta \Omega_{F e M n}^{\gamma \rightarrow \varepsilon}+X_{F e} X_{A l}\left(X_{F e}+X_{A l}\right)^{-1} \Delta \Omega_{F e A l}^{\gamma \rightarrow \varepsilon} \\
& +X_{F e} X_{S i}\left(X_{F e}+X_{S i}\right)^{-1} \Delta \Omega_{F e S i}^{\gamma \rightarrow \varepsilon}+X_{F e} X_{C}\left(X_{F e}+X_{C}\right)^{-1} \Delta \Omega_{F e C}^{\gamma \rightarrow \varepsilon} \cdots \cdots
\end{aligned}
$$

where $X_{i}$ is the mole fraction of the compound $i$. Thermodynamic data are listed up in Table 2. The interaction parameter $\Delta \Omega_{F e s i}^{\gamma \rightarrow \varepsilon}$ was calculated with the THERMO-CALC program [25]. According to a thermodynamic model, the stacking fault energy of fcc alloys is expressed by the follwing eq. (2) [18]:

$$
\gamma_{f c c}=2 \rho \Delta G^{\gamma \rightarrow \varepsilon}+2 \sigma^{\gamma / \varepsilon}
$$

where $\rho$ is the density of atoms in a closed packed plane in moles per unit area (here $: 2,53 \cdot 10^{-5} \mathrm{~mol} / \mathrm{m}^{2}$ ) and $\sigma^{\gamma / \varepsilon}$ is the $\gamma / \varepsilon$ interfacial energy which is not available for the studied alloy. Therefore, the value $\sigma^{\gamma / \varepsilon}=$ $10 \mathrm{~mJ} / \mathrm{m}^{2}$ published for the austenitic stainless steel Fe-(16-8)Cr-(12-14) Ni [19] was employed. The calculated stacking fault energy is plotted as a function of temperature in Figure 6 . The strain-induced $\varepsilon^{-}$ martensite was detected by $\mathrm{X}$-ray diffraction in strained samples at temperatures below $0{ }^{\circ} \mathrm{C}$. This is in

\begin{tabular}{|c|c|c|}
\hline \multicolumn{3}{|c|}{$\begin{array}{l}\text { Free energy differences between } \gamma \text { and } \varepsilon \\
\Delta G^{\gamma \rightarrow \varepsilon}={ }^{0} \Delta G^{\varepsilon}-{ }^{0} \Delta G^{\gamma} / \mathrm{J} / \mathrm{mol}, T / K\end{array}$} \\
\hline $\mathrm{Fe}$ & $\therefore \Delta \mathrm{G}^{\gamma \rightarrow \varepsilon}=-1828,4+4,686 \mathrm{~T}$ & {$[20]$} \\
\hline $\mathrm{Mn}$ & $: \Delta \mathrm{G}^{\mathrm{Y} \rightarrow \varepsilon}=3970-1,66667 \mathrm{~T}$ & {$[21]$} \\
\hline $\mathrm{Si}$ & $\Delta \mathrm{G}^{\gamma \rightarrow \varepsilon}=-1800+\mathrm{T}$ & {$[22]$} \\
\hline $\mathrm{Al}$ & $\Delta \mathrm{G}^{\gamma \rightarrow \varepsilon}=5481,04-1,799 \mathrm{~T}$ & {$[23]$} \\
\hline C. & $: \Delta G^{\gamma \rightarrow \varepsilon}=-24595,12$ & {$[24]$} \\
\hline \multicolumn{3}{|c|}{$\begin{array}{l}\text { Interaction parameter differences between } \gamma \text { and } \varepsilon \\
\Delta \Omega^{\gamma \rightarrow \varepsilon}=\Delta \Omega^{\varepsilon}-\Delta \Omega^{\gamma} / \mathrm{J} / \mathrm{mol}, \mathrm{T} / \mathrm{K}\end{array}$} \\
\hline FeMn & $: \Delta \Omega^{\gamma \rightarrow \varepsilon}=-10836+22886 X_{\mathrm{Mn}}$ & {$[10]$} \\
\hline $\mathrm{FeSi}$ & $: \Delta \Omega^{\gamma \rightarrow \varepsilon}=1780$ & {$[25]$} \\
\hline $\mathrm{FeAl}$ & $: \Delta \Omega^{\gamma \rightarrow \varepsilon}=3323$ & {$[24]$} \\
\hline $\mathrm{FeC}$ & $\Delta \Omega^{\gamma \rightarrow \varepsilon}=42500$ & {$[18]$} \\
\hline
\end{tabular}
good agreement with the observation that strain-induced $\varepsilon$-martensite is predominantly formed if the stacking fault energy is about $20 \mathrm{~mJ} / \mathrm{m}^{2}$ [8]. However, the selected thermodynamic data and interaction parameter are not precise enough at very low temperature.

Table 2 : Thermodynamic data used for the calculation

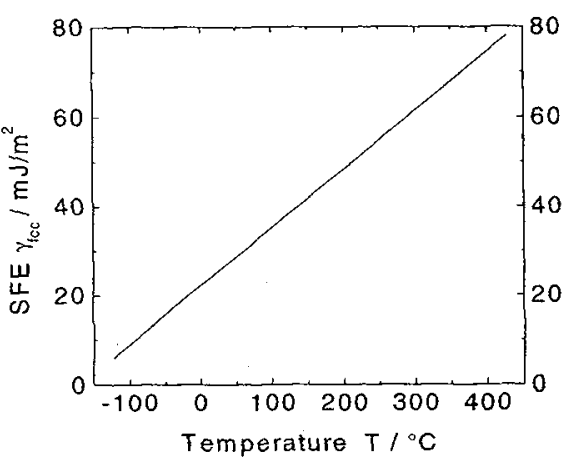

Figure 6 : Stacking fault energy (SFE) vs. Temperature 


\section{SUMMARY}

Extensive mechanical twinning and a certain amount of martensitic $\gamma \rightarrow \varepsilon$ phase transformation in austenitic manganese steels cause their extraordinary tensile properties, such as high strain hardening and large uniform elongations up to extremely high strain rates. The Fe-25Mn-3Si-3Al alloy exhibit the highest tensile elongation of about $82 \%$ at room temperature. The temperature dependence of the tensile elongation of this alloy was investigated and correlated to mirostructural features. X-ray diffraction and TEM studies reveal that increasing elongation with decreasing temperature is due to twin formation as the accommodation mechanism. The high elongations are due to localized multiple necking. The primary appearance of $\varepsilon$-martensite was detected in strained samples at room temperature by TEM. However, Xray diffraction technique seemend to be not so sensitive for detecting small sizes and portions of $\varepsilon$ martensite. With decreasing temperature the amount of strain-induced $\varepsilon$-martensite increases and becomes the main accommodation mechanism. At $-196{ }^{\circ} \mathrm{C}$ the alloy exhibit a total elongation of $65 \%$. The formation of strain-induced $\varepsilon$-martensite and mechanical twinning enhanced the tensile elongation due to retardation of necking. The calculated stacking fault energies and $\Delta \mathrm{G}^{\gamma \rightarrow \varepsilon}$ values, based on a regular solution approach, are consistent with the fact that $\varepsilon$-martensite is formed in austenitic ultra high maganese steels where $\gamma_{\mathrm{fcc}} \leq 20 \mathrm{~mJ} / \mathrm{m}^{2}$. Investigations on the $\mathrm{Fe}-25 \mathrm{Mn}-3 \mathrm{Si}-3 \mathrm{Al}$ alloy at high strain rates even beyond $10^{3} \mathrm{~s}^{-1}$ reveals excellent ductility and strength properties. Total elongation of $80 \%$ and true tensile strength of $1000 \mathrm{MPa}$ were achieved.

\section{Acknowledgments}

The authors would like to thank Prof. L.W. Meyer and Dipl.-Ing. L. Krüger, TU Chemnitz-Zwickau, for performing the high strain rate experiments and Prof. G. Inden for calculating the interaction parameter with the THERMO-CALC program.

\section{References}

[1] Y.G. Kim, J.M. Han, J.S. Lee : Mater. Sci. Eng. A, A114, (1989), 51

[2] Y. Tomota, M. Strum, J.W. Morris Jr. : Metall. Trans. A, 17A, (1986), 537

[3] A. Sato, K. Soma, T. Mori : Acta Metall., Vol 30, (1982), 1901-07

[4] A. Holden, J.D. Bolten, E.R. Petty : J. Iron Steel Inst., (1971), Sept., 721

[5] C.H. White, R.W.K. Honeycombe : J. Iron Steel Inst., 200, (1962), 457

[6] H. Schumann : Arch. Eisenhüttenwes., 38, (1967), 647

[7] S. Cotes, M. Sade, A. Fernandez Guillermet : Metall. Mat. Trans. A, Vol 26A, (1995), 1957-69

[8] S. Takaki, T. Furuya, Y. Tokunaga : ISIJ Int., Vol 30, (1990), No.8, 632-38

[9] K. Sato, M. Ichinose, Y. Hirotsu, Y. Inoue : ISIJ Int., Vol 29, (1989), No.10, 868-77

[10] K. Ishida, T. Nishizawa : Trans. Jpn. Inst. Met., 15, (1974), 225

[11] R.E. Schramm, R.P. Reed : Metall. Trans. A, 6A, (1975), 1345

[12] E. Schmidtmann, K. Westmann : Archiv für das Eisenhüttenwesen, Heft 6, (1970), 577

[13] J. Kühne: Wiss. Z. Techn. Hochsch. Magdeburg, 24, (1980), Heft 1

[14] Y. Tomita, T. Iwamoto : Int. J. Mech. Sci., No 12, (1995), 1295-1305

[15] S.S. Hecker, M.G. Stout, K.P. Staudhammer, J.L. Smith : Metall. Trans. A, 13A, (1982), 619

[16] S.H. Hong, Y.S. Han : Scripta Metallurgica et Materialia, Vol. 32, No. 9, (1995), 1489-94

[17] Y.G. Kim, Y.S. Park, J.K. Han : Metall. Trans. A, 16A, (1985), 1689

[18] P.H. Adler, G.B. Olsen, W.S. Owen : Metall. Trans. A, 17A, (1986), 1725

[19] G.B. Olsen, M. Cohen : Metall. Trans A, 7A, (1976), 1897

[20] D. Dew-Hughes, L. Kaufman : CALPHAD, Vol. 3, (1979), 175

[21] J.F. Breedis, L. Kaufman : Metall. Trans., Vol 2, (1971), 2359-71

[22] A.T. Dinsdale: CALPHAD, Vol. 15, (1991), 317

[23] L. Kaufmann : CALPHAD, Vol. 1, (1977), 7

[24] W.S. Yang, C.M. Wan : J. of Mater. Sci., Vol. 25, (1990), 1821

[25] B. Sundman, B. Jansson, J.-O. Anderson : CALPHAD, Vol. 9, (1985), 153 